\title{
Unmanned aerial system nadir reflectance and MODIS nadir BRDF-adjusted surface reflectances intercompared over Greenland
}

\author{
John Faulkner Burkhart ${ }^{1,2}$, Arve Kylling ${ }^{3}$, Crystal B. Schaaf ${ }^{4}$, Zhuosen Wang ${ }^{5,6}$, Wiley Bogren ${ }^{7}$, Rune Storvold ${ }^{8}$, \\ Stian Solbø ${ }^{8}$, Christina A. Pedersen ${ }^{9}$, and Sebastian Gerland ${ }^{9}$ \\ ${ }^{1}$ Department of Geosciences, University of Oslo, Oslo, Norway \\ ${ }^{2}$ University of California, Merced, CA, USA \\ ${ }^{3}$ Norwegian Institute for Air Research, Kjeller, Norway \\ ${ }^{4}$ School for the Environment, University of Massachusetts Boston, Boston, MA, USA \\ ${ }^{5}$ NASA Goddard Space Flight Center, Greenbelt, MD, USA \\ ${ }^{6}$ Earth System Science Interdisciplinary Center, University of Maryland, College Park, MD, USA \\ ${ }^{7}$ U.S. Geological Survey, Flagstaff, AZ, USA \\ ${ }^{8}$ Norut-Northern Research Institute, Troms $\emptyset$, Norway \\ ${ }^{9}$ Norwegian Polar Institute, Fram Centre, Troms $\varnothing$, Norway
}

Correspondence to: John Faulkner Burkhart (john.burkhart@geo.uio.no)

Received: 12 November 2016 - Discussion started: 15 December 2016

Revised: 17 May 2017 - Accepted: 18 May 2017 - Published: 4 July 2017

\begin{abstract}
Albedo is a fundamental parameter in earth sciences, and many analyses utilize the Moderate Resolution Imaging Spectroradiometer (MODIS) bidirectional reflectance distribution function (BRDF)/albedo (MCD43) algorithms. While derivative albedo products have been evaluated over Greenland, we present a novel, direct comparison with nadir surface reflectance collected from an unmanned aerial system (UAS). The UAS was flown from Summit, Greenland, on $210 \mathrm{~km}$ transects coincident with the MODIS sensor overpass on board the Aqua and Terra satellites on 5 and 6 August 2010. Clear-sky acquisitions were available from the overpasses within $2 \mathrm{~h}$ of the UAS flights. The UAS was equipped with upward- and downward-looking spectrometers $(300-920 \mathrm{~nm})$ with a spectral resolution of $10 \mathrm{~nm}$, allowing for direct integration into the MODIS bands 1,3 , and 4 . The data provide a unique opportunity to directly compare UAS nadir reflectance with the MODIS nadir BRDF-adjusted surface reflectance (NBAR) products. The data show UAS measurements are slightly higher than the MODIS NBARs for all bands but agree within their stated uncertainties. Differences in variability are observed as expected due to different footprints of the platforms. The UAS
\end{abstract}

data demonstrate potentially large sub-pixel variability of MODIS reflectance products and the potential to explore this variability using the UAS as a platform. It is also found that, even at the low elevations flown typically by a UAS, reflectance measurements may be influenced by haze if present at and/or below the flight altitude of the UAS. This impact could explain some differences between data from the two platforms and should be considered in any use of airborne platforms.

\section{Introduction}

Albedo, the ratio of reflected to incident energy at the surface of the earth, is a fundamental parameter in energy balance computations, and therefore any prediction of climate must account for albedo through a parameterization process (Henderson-Sellers and Wilson, 1983). Generally climate models rely on simplified estimations of albedo as singlevalue climatological means of broadband albedo that are a function of seasonal changes in surface characteristics and the presence of snow (Curry and Schramm, 2001). For mod- 
eling snow and ice melt processes on the earth's surface, albedo is a critical parameter, providing the most coarse adjustment with respect to available energy to drive melt. Satellite instruments play an important role in providing a characterization of albedo of the surface of earth that is relevant for climate and earth system modeling.

Stroeve et al. (2005) and more recently Stroeve et al. (2013) have carefully evaluated the Moderate Resolution Imaging Spectroradiometer (MODIS) albedo products over Greenland. Several further studies have evaluated presently available satellite products and compared these products with ground-based observations. This recent body of work has been largely spurred by the 2012 melt events on the Greenland Ice Sheet (GrIS). These events, recorded by MODIS satellite observations, have been linked to albedo feedback stemming from thermodynamic processes (Box et al., 2012). Dumont et al. (2014), Goelles et al. (2015), and Keegan et al. (2014) attribute some of the darkening to deposition of soot from forest fires, pollution, and dust, while others have linked the changes predominately to delivery of warm water vapor and low-level clouds (Bennartz et al., 2013; Miller et al., 2015).

Due to the impact on snow and ice albedo, the Intergovernmental Panel on Climate Change (IPCC) identified black carbon on snow as an important process driving changes in the cryospheric energy balance with significant associated uncertainty (IPCC, 2013). These findings are based on research that has focused on the theoretical response of snow to black carbon deposition (Warren and Wiscombe, 1980; Hansen and Nazarenko, 2004). Subsequent studies have shown that small changes in snow albedo globally may have significant impact on the top-of-atmosphere forcing and could be driving a component of the Arctic warming witnessed today (Flanner et al., 2009). However, presenting a distinct challenge, Warren (2012) suggests that the changes anticipated from this effect are below the present-day measurement capabilities.

Numerous studies have used ground-based measurements to compare and validate satellite sensor data, a necessary process to assess accuracy of the observations, and particularly to understand the variability that may be missed by different sensor footprint scales. A seminal study is that of Salomonson and Marlatt (1971), who conducted an evaluation of surface reflectance conditions for application to retrievals from the Medium-Resolution Infrared Radiometer (MRIR) instrument aboard the Nimbus II and III satellites. The study focused on the measurement of bidirectional reflectance distribution function (BRDF) over a variety of terrestrial surfaces. Appreciable anisotropy on all the surfaces was found, leading to the conclusion of the importance of using a BRDF model for satellite retrievals - a standard application today (Schaaf et al., 2002; Jin, 2003; Román et al., 2009; Ju et al., 2010; Wang et al., 2014).

Wright et al. (2014) intercompare ground-based spectral observations from an ASD FieldSpec spectroradiometer at Summit station with both the MODIS Collection 5 (C5) and
Collection 6 (C6) data, and show a marked improvement of the MODIS C6 retrieval. Prior studies relied predominately on existing GrIS fixed station data from the Greenland Climate Network (GC-Net) of automatic weather stations (Box et al., 2012; Stroeve et al., 2005, 2006, 2013). To our knowledge most investigations have compared ground-based measurements of albedo with satellite albedo products. While this is valuable, one must recognize that albedo products are developed through a processing chain of models and therefore do not represent a direct measurement, making comparisons complicated.

Recently, the advent of relatively low-cost unmanned airborne systems (UASs) has created a rush to utilize this novel platform to provide unique data sets otherwise unobtainable without manned flight. Furthermore, UASs provide a unique niche in the ability to characterize cryospheric surfaces in relatively localized regions at higher resolutions than may be possible with traditional aircraft, and they certainly offer the potential to extend the observational range of a traditional ground-based campaign (Bhardwaj et al., 2016). In one of the first applications of a UAS for cryospheric characterization, Hakala et al. (2014) demonstrated the potential for BRDF measurements from a simple quadcopter. Immerzeel et al. (2014) used a UAS to characterize glacial dynamics in the Himalaya, while numerous other have recently applied structure from motion photogrammetry to several applications related to snow and ice surfaces (e.g., Jagt et al., 2015; Ryan et al., 2015; Rippin et al., 2015). Most recently, Ryan et al. (2017) have attempted to use cameras to measure albedo from a UAS on board a fixed-wing platform on the perimeter of Greenland.

Herein we provide a first-of-a-kind, "apples-to-apples" evaluation of the accuracy of the MODIS nadir BRDFadjusted reflectance (NBAR) retrievals through intercomparison with reflectance observed from a UAS platform over Greenland. The advent of UASs presents an immense opportunity to spatially assess the accuracy of satellite sensors, versus simple validation against ground point observations. However, as discussed in this work, there are a host of complications that must be considered. We explore those further herein.

In this study, spectral reflectance measurements made from a UAS flying in the dry snow region near Summit, Greenland, are used to evaluate sub-pixel-scale variability of the MODIS NBAR retrievals. The campaign was conducted in 2010 and provides data for two transects on separate days coincident with the near nadir subtrack of the MODIS instrument overpasses. Due to the pristine nature of the snow surface in this area, and the limited influence of aerosols and warm temperatures, albedo and reflectance variability in this region is expected to be less than $10 \%$, and potentially as low as $3 \%$ - within the $5 \%$ stated accuracy of the MODIS data sets. The standard MODIS products retrieve narrowband reflectance and then use a narrowbandto-broadband algorithm to convert the discrete narrowband 
measurements into a broadband albedo (Schaaf et al., 2002; Stroeve et al., 2005). Our approach allows a direct comparison with MODIS, as the UAS observations have a high spectral resolution and therefore may be integrated directly to narrowband reflectance values using the MODIS response functions for bands 1, 3, and 4 (see Sect. 5).

The "Variability of Albedo Using Unmanned Aerial Vehicles" (VAUUAV) project had a primary objective of evaluating whether present-day satellite observations allow the capacity to evaluate the impact of aerosols on albedo variability across a cryospheric landscape and to provide input for validation of theoretical modeling. However, through our work, we discovered that the application of UAS to obtain data suitable for validation of MODIS data sets is greatly complicated by aspects of the platform that to date have not been addressed, particularly with respect to albedo. Therefore, as we have the capability, we have chosen to conduct the comparison with reflectance - providing a direct evaluation of the platform capabilities. Further we have attempted to address several of the complex issues that result from the UAS in this analysis and otherwise highlight the potential for uncertainty in the observations. In Sect. 2 we present the UAS measurement platform. Section 3 describes radiative transfer calculations, while Sect. 4 describes the data selection, and Sect. 5 describes the MODIS data used for this study. A comparison and discussion of the MODIS and UAS data are presented in the Sect. 6 followed by a summary and conclusion.

\section{Surface reflectance measurements from an unmanned aerial system}

The Cryowing (see Sect. 2.1) UAS performed several flights during the summer of 2010 in the region of Summit, Greenland, at the Greenland Environmental Observatory (http:// www.geosummit.org). The flights were designed to measure the downwelling irradiance and the upwelling nadir radiance as discussed further in Sect. 2.2.

Two of the flights were specifically designed to be closely aligned with MODIS overpasses and were flown as close in time as possible to the satellite overpasses. On 5 and $6 \mathrm{Au}-$ gust 2010, the UAS completed a flight pattern with coverage over a region which was nearly coincident with the MODIS sensor overpass on board the Aqua and Terra satellites. On both days, clear-sky acquisitions are available from overpasses within $2 \mathrm{~h}$ of the UAS flights. The flight pattern covered $210 \mathrm{~km}$ ground distance and was completed autonomously for a duration of over $2 \mathrm{~h}$. From the UAS observations we develop a nadir data set suitable for direct comparison with the MODIS NBAR products with a reduced reliance on a model chain.

\subsection{The Cryowing UAS}

The Cryowing UAS is an autonomous fixed-wing airborne sensor platform developed in Norway. It has a maximum takeoff weight of $30 \mathrm{~kg}$, payload capacity of $15 \mathrm{~kg}$ including fuel, and a wingspan of $3.8 \mathrm{~m}$. The Cryowing is powered by a two-stroke engine, fueled by a petrol-oil mixture. The normal cruising speed is $100-120 \mathrm{~km} \mathrm{~h}^{-1}$, with a range of up to $500 \mathrm{~km}$ or $5 \mathrm{~h}$ flight. The Cryowing has a $2500 \mathrm{~m}$ dynamic altitude range, with a $5000 \mathrm{~m}$ absolute altitude cap. A dedicated GPS independent from the payload is used for navigation and autopilot control. While the Cryowing is capable of autonomous control for the full period of a flight, in practice a skilled technician is present to control launch and landing via radio control. Once stable flight is achieved, communication with the UAS is maintained for the duration of the flight using a radio modem or Iridium satellite modem.

A standard suite of instruments is deployed on the Cryowing. This includes a meteorological package, two inertial measurement units (IMUs), and two GPS systems, as well as the computer and communications systems responsible for flight control and ground station contact. The meteorological package measures air pressure, temperature, and humidity, while the flight computer and systems record aircraft position and altitude. Position is recorded as altitude in meters along with latitude and longitude, while attitude is recorded in quaternion form. In this analysis, platform attitude was converted to the azimuth and zenith angles for subsequent radiative transfer modeling as discussed in Sect. 3. Position and attitude variables were recorded at a frequency of $100 \mathrm{~Hz}$ by the IMU.

\subsection{UAS-based surface reflectance}

In the VAUUAV payload configuration, the Cryowing is equipped with two TriOS RAMSES spectroradiometers to measure reflected and incoming radiation in the visible spectrum (VIS). The upward-facing sensor, measuring incoming radiation, has a cosine-corrected fore-optic made of synthetic fused silica, transparent to $190 \mathrm{~nm}$, to measure full-sky hemisphere irradiance. The nadir-facing sensor has a Gershun tube restricted $7^{\circ}$ field-of-view (FOV) fore-optic, measuring reflected radiance emanating from a footprint beneath the plane. At a cruise altitude of $250 \mathrm{~m}$ the footprint is on the order of $30 \mathrm{~m}$ in diameter.

Details of the TriOS sensors and the configuration used can be found in Nicolaus et al. (2010). For completeness, we describe the essential characteristics of the spectral radiometers here. The TriOS RAMSES ACC-2 VIS hyper-spectral radiometers are based on a miniature spectrometer with a wavelength range from 310 to $1100 \mathrm{~nm}$ and spectral resolution and accuracy of 3.3 and $0.3 \mathrm{~nm}$, respectively. TriOS uses the VIS-near-infrared (NIR) specification of the spectroradiometers (wavelength range from 360 to $900 \mathrm{~nm}$ ) to postcalibrate the instruments to a wavelength range from 320 to 
$950 \mathrm{~nm}$. Software controlling the instruments enables an automatic adjustment of the integration time for each measurement, ranging between 4 and $8192 \mathrm{~ms}$.

There are two versions of the sensors, one containing an inclination and pressure sensor, and one without. For our purposes, these additional components were not required, as a part of the standard suite of measurements aboard the UAS includes highly accurate inclination from the IMU. As the sensors were initially designed for water quality applications, they are built to be water resistent to a depth of $300 \mathrm{~m}$. This creates additional weight due to the robust design of the casing and sealed body of the sensors. In order to use the sensors in the UAS, modifications from the sensors described in Nicolaus et al. (2010) were required. To reduce the length and weight of the sensors as available from the manufacturer (and described in Nicolaus et al., 2010), the solid-steel casing was removed and replaced with a lightweight aluminum version. This reduced the weight of the sensors significantly from the initial $833 \mathrm{~g}$ to less than $400 \mathrm{~g}$.

The in situ observations presented in this study provide the downwelling irradiance $\left(E\left(\theta_{\mathrm{i}}\right)\right)$ and the upwelling radiance $L_{\mathrm{r}}\left(\theta_{\mathrm{i}}, \phi_{\mathrm{i}} ; \theta_{\mathrm{r}}, \phi_{\mathrm{r}}\right)$ with a field of view of $7^{\circ}$ in the direction $\theta_{\mathrm{r}}=\pi / 2, \phi_{\mathrm{r}}=0$ for incident zenith (azimuth) angle $\theta_{\mathrm{i}}\left(\phi_{\mathrm{i}}\right)$.

The nadir reflectance measured by the UAS is

$$
\rho=\frac{\pi L_{\mathrm{r}}\left(\theta_{\mathrm{i}}, \phi_{\mathrm{i}} ; \pi / 2,0\right)}{E\left(\theta_{\mathrm{i}}\right)},
$$

which may be directly compared with the NBAR from MODIS (Schaaf et al., 2002). All wavelength dependence in Eq. (1) has been omitted for clarity.

Our instrument measures spectral reflectance from 320 to $950 \mathrm{~nm}$ with $3.3 \mathrm{~nm}$ per pixel resolution with a $3 \mathrm{~nm}$ oversampling, making an effective $10 \mathrm{~nm}$ resolution, allowing us to integrate across the MODIS bands 1, 3, and 4 for a direct intercomparison. The spectral response for MODIS bands 1, 3, and 4 are shown in Fig. 1. The wavelengths covered by these bands are provided from the MODIS specifications website: http://modis.gsfc.nasa.gov/ about/specifications.php. For comparison with the MODIS NBAR data (see Sect. 5), the UAS spectra were multiplied with the MODIS spectral band functions (Fig. 1), and the respective NBARs calculated according to Eq. (1).

\subsection{Radiance offset correction}

To establish the relative sensitivity of the radiance and irradiance sensors, measurements were made on the ground with the two UAS sensors co-located together with a reference irradiance sensor looking skyward. The relative sensitivity of the radiance and irradiance sensors was calculated, and a third-order polynomial was fit to this ratio in the wavelength region relevant for comparison of UAS and MODIS data. All measured radiance spectra were corrected for the wavelength-dependent offset using the polynomial fit.

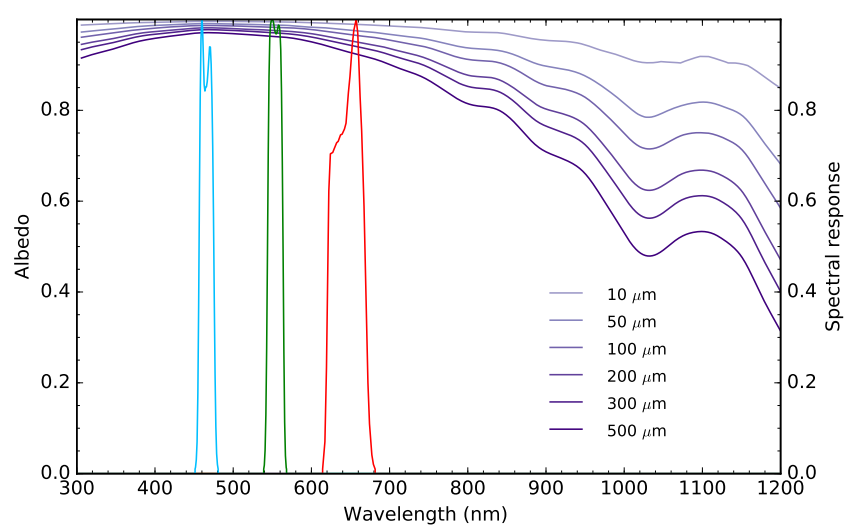

Figure 1. The pure-snow albedo as a function of wavelength for snow grain sizes between 10 and $500 \mu \mathrm{m}$. Also shown in the thicker lines is the MODIS spectral response for band 3 (blue), 4 (green), and 1 (red). The spectral response data were obtained from http: //mcst.gsfc.nasa.gov/calibration/parameters.

\subsection{Cosine error correction}

The uplooking sensor measures the irradiance, requiring a detector with a hemispheric cosine response fore-optic. In reality the angular response of cosine detector deviates from a cosine shape. Cosine error corrections have been thoroughly investigated for UV spectrometers (see for example Bais et al., 1998). The cosine error correction depends on the atmospheric state when the measurements were made. The deviations typically become larger as the incidence angle increases, implying that measured irradiance is underestimated compared with an instrument with a perfect angular response. This underestimate may be corrected for providing that the sky conditions during the measurements are known and that the angular response of the instrument is known (Bais et al., 1998).

The TriOS sensors are laboratory certified and have undergone calibration by the manufacturer prior to each field season. For the zenith angles encountered during the flights $\left(<70^{\circ}\right)$ we expect the deviation from a perfect cosine response to be less than $2 \%$.

\subsection{Angular sensitivity}

The uplooking detector must be properly leveled to allow accurate measurements of the downwelling irradiance (Bogren et al., 2016). This may be achieved, for example, by stabilizing the measurement platform (Wendisch et al., 2001) or by mounting the instrument with a tilt such that the instrument is leveled during flight. The latter approach was adopted with the UAS; however, this requires that the platform is stable during flight. To estimate the effect of angular changes on a fixed detector, radiative transfer simulations were performed as described below in Sect. 3. The roll angle of the aircraft, and thus the detector, was changed between 0 and $10^{\circ}$, while 
the yaw angle was changed from from 0 to $360^{\circ}$. The radiation field was simulated for a cloudless sky over a snowcovered surface. The response relative to a leveled detector is shown in Fig. 3 for a solar zenith angle of $55.66^{\circ}$ and azimuth of $0^{\circ}$. If the detector has a roll angle of $10.0^{\circ}$ and yaw angle $90^{\circ}$ with respect to the sun, implying that it is facing away from the sun, the detector will measure only about $80 \%$ of the radiation of a leveled detector.

Similarly, a detector shifted such that it faces the sun will overestimate the radiation compared to a leveled detector. The results presented in Fig. 3 are for a cloudless sky. For an overcast sky, with the aircraft flying below the cloud, the change in angular response is negligible with given azimuth and roll angles (Bogren et al., 2016). The effect of roll and yaw angles on the measurements will change with solar zenith angle, surface albedo, sky conditions, and wavelength. As such they are challenging to correct for when the aircraft is moving around due to changes in the flying directions or changing wind conditions. For the analysis below, UAS data were screened and selected for stable flight conditions. In addition a tilt correction was applied to the direct portion of the irradiance impinging the upward-facing sensor. As presented by Bogren et al. (2016), the response of a sensor tilted $\theta_{\mathrm{t}}$ degrees and rotated $\phi$ degrees relative to the sun is

$R^{\mathrm{t}}\left(\theta_{\mathrm{t}}, \phi\right)=\cos \left(\theta_{0}-\theta_{\mathrm{t}} \cos (\phi)\right)$,

where $\theta_{0}$ is the solar zenith angle. For a leveled sensor $R^{1}=$ $\cos \left(\theta_{0}\right)$. The tilt error correction is largest for the direct part of the irradiance and negligible for the diffuse part (Bogren et al., 2016). We thus tilt-correct the measured downwelling irradiance $E_{\mathrm{m}}$ as follows:

$E=f E_{\mathrm{m}} R^{1} / R^{\mathrm{t}}+(1-f) E_{\mathrm{m}}$.

Here the first term on the right side is the tilt correct direct contribution, and the second term is the uncorrected diffuse contribution. Furthermore, $f$ is the wavelength-dependent direct / global irradiance ratio. It was estimated by the libRadtran model, described in Sect. 3, to be 0.98, 0.92, and 0.85 for MODIS bands 1, 4, and 3, respectively.

Due to dismounting and remounting for maintenance, or from the thrust of the catapult at launch, the instrument package may become slightly disoriented. Thus $\theta_{\mathrm{t}}$ and $\phi$ may be offset. During the analysis it was found that $\theta_{\mathrm{t}}$ should be reduced by $0.7^{\circ}$, and a $10^{\circ}$ azimuth offset added.

\subsection{Atmospheric corrections}

During the flights the altitude of the UAS varied between 270 and $320 \mathrm{~m}$ above the surface. The atmosphere between the surface and the aircraft may influence the aircraft nadir measurements. To estimate the impact of the intervening atmosphere, UAS radiance and irradiance spectra were simulated for noon (solar zenith angle of $55.66^{\circ}$ ) at Summit for elevations between 270 and $320 \mathrm{~m}$ a.g.l. in steps of $10 \mathrm{~m}$. The simulated spectra were multiplied with the MODIS band 1, 3 , and 4 response functions (Fig. 1), and the corresponding UAS nadir measurements were integrated to the corresponding narrow bandwidths. It was found that the atmosphere between the aircraft and surface caused less than $0.2 \%$ changes in the band 1 nadir reflectance and less than $0.04 \%$ difference in the bands 3 and 4 nadir reflectance. Thus, the nadir reflectance derived from the UAS were not corrected for the intervening atmosphere.

\subsection{Error estimate}

Estimates of the measurement error are inherently difficult to make and require time resources often not available in the field. However, best estimates of the measurment error from various sources are assumed and used to calculate a total error as summarized below.

Ideally NBAR measurements should be made over flat surfaces. As shown in Siegfried et al. (2011), the region around Summit is sufficiently flat with a slope of less than $2 \mathrm{~m} \mathrm{~km}^{-1}$ in the east-west direction and less than $0.5 \mathrm{~m} \mathrm{~km}^{-1}$ in the north-south orientation. Our flights were further north from Summit than measured by Siegfried et al. (2011), but data from available digital elevations maps from the Greenland Ice Mapping Project (Howat et al., 2014) confirm the area covered by the UAS flights is indeed flat. However, smallscale wind-blown snow features can not be ruled out. This is potentially the largest source of error in the analysis. Sustruggi structures on the snow surface can cause strong scattering and geometric optical effects. This variability is difficult to resolve or explicitly model. However, effects of scattering will be reduced by integrating over the footprint of the measurement. An uncertainty of $0.5 \%$ is assumed due to measurements over non-flat surfaces.

The offset between the up- and downlooking sensors was measured and corrected for as explained in Sect. 2.3. A remaining error of $0.2 \%$ is assumed for the offset correction.

The tilt error has been corrected for as described in Sect. 2.5. The attitude is specified to have an uncertainty of $2 \%$. The uncertainty in the data due to remaining tilt error and assumption about the direct / global radiation ratio is thus taken to be $2 \%$.

According to the manufacturer, the cosine error is better than $6-10 \%$, depending on wavelength, while for the $7^{\circ}$ detector the angular response is better than $6 \%$. The cosine error typically increases with zenith angle in addition to wavelength. The error will thus be largest for large solar zenith angles as found at high latitude. No cosine response measurements were available for a detailed assessment of the cosine error. A $2 \%$ cosine error correction has been applied to the uplooking sensor (Sect. 2.4). A $2 \%$ cosine error uncertainty is assigned to the measurements. The downlooking sensor is exposed to diffuse radiation, and the error in the angular response is of less concern. 

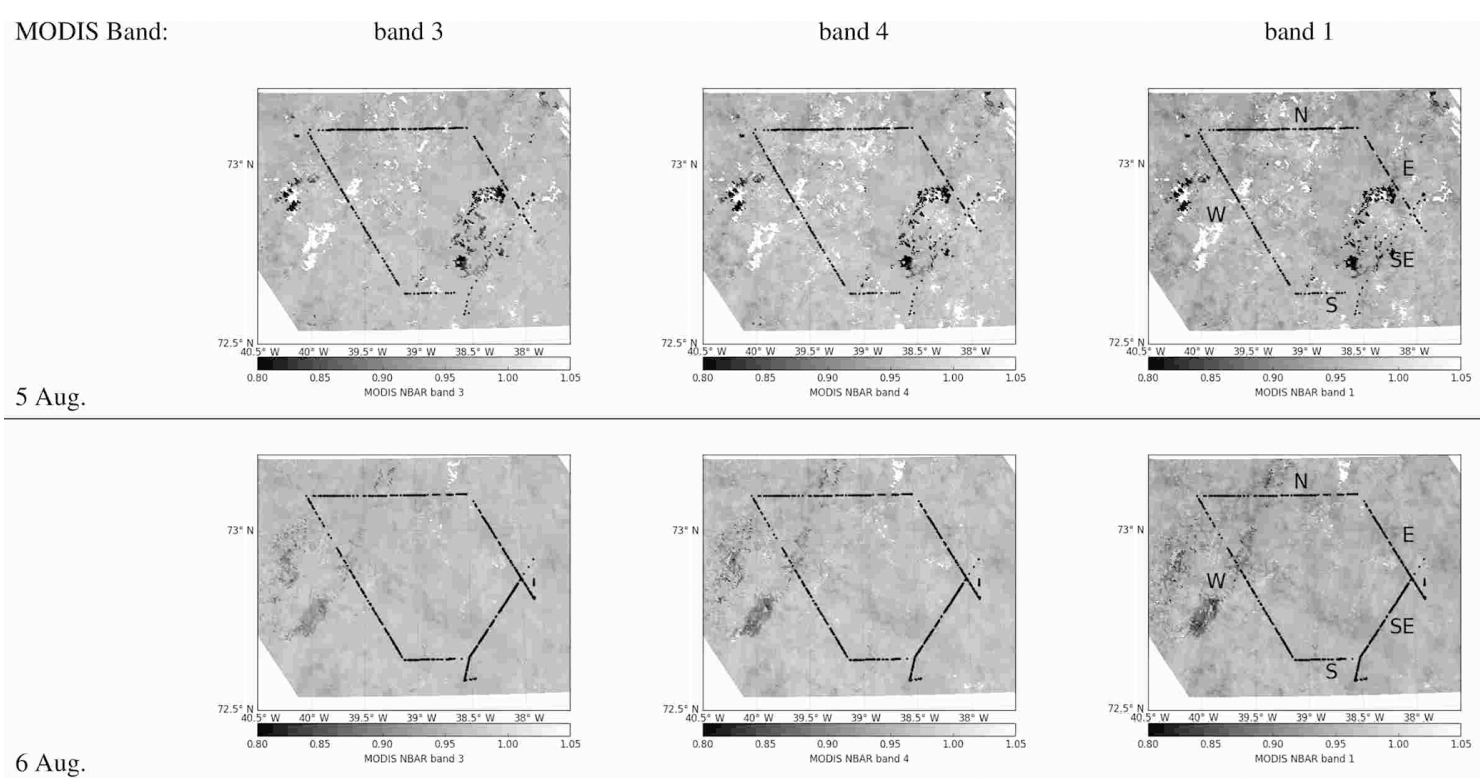

Figure 2. MODIS blue (band 3), green (band 4), and red (band 1) NBARs for 5 August (upper row) and 6 August (lower row) 2010. The black dots represent UAS data which were recorded during stable flight conditions. White areas indicate missing data.

For an integration time of $8 \mathrm{~s}$ the manufacturer gives a noise equivalent irradiance (NEI) of $0.4 \mu \mathrm{W} \mathrm{m}^{-2} \mathrm{~nm}^{-1}$ at 400 and $500 \mathrm{~nm}$, and $0.6 \mu \mathrm{W} \mathrm{m}^{-2} \mathrm{~nm}^{-1}$ at $700 \mathrm{~nm}$ for the cosine response detector. For the $7^{\circ}$ detector the NEI is $0.25 \mu \mathrm{W} \mathrm{m}{ }^{-2} \mathrm{~nm}^{-1}$. The integration times during the flights were shorter; thus a conservative estimate of the NEI during the flights is $0.5 \%$.

We assume that all errors are independent of wavelength. Squaring the errors gives a total error in the UAS reflectance of $2.9 \%$.

\section{Radiative transfer simulations}

As a part of the data reduction and analysis process, and to assess the sensitivity to radiative processes in the atmosphere (Sect. 6), we conducted radiative transfer simulations. These were performed to test the UAS sensitivity to changes in pitch, roll, and yaw angles (Sect. 2.5 above), and to simulate cloudless shortwave broadband radiation at Summit (Sect. 4 below). The libRadtran radiative transfer package was utilized for these calculations (Mayer and Kylling, 2005; Emde et al., 2016). The molecular absorption was parameterized with the LOWTRAN band model (Pierluissi and Peng, 1985), as adopted from the SBDART code (Ricchiazzi et al., 1998). The $C$ version of the DISORT radiative transfer solver (Stamnes et al., 1988; Buras et al., 2011) was utilized. The snow albedo model of Wiscombe and Warren (1980) as implemented in the libRadtran software package was used to calculate the spectral surface reflectance as shown in Fig. 9. The sub-Arctic summer atmosphere (Anderson et al., 1986) was used, and the surface altitude set to $3126 \mathrm{~m}$.

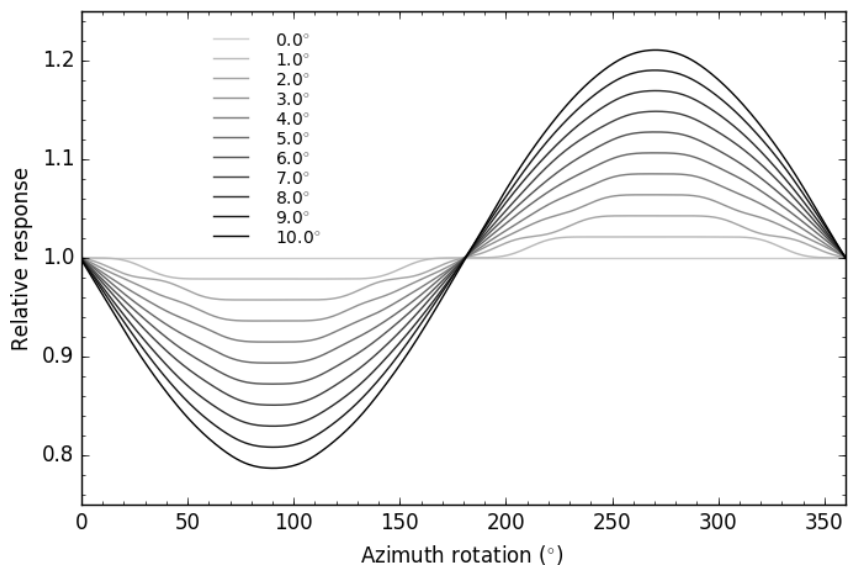

Figure 3. The relative response when tilting (from 0 to $10^{\circ}$ ) and rotating around azimuth an irradiance sensor on board a platform $300 \mathrm{~m}$ above a snow surface. The solar zenith (azimuth) angle is $55.66^{\circ}\left(0^{\circ}\right)$. The wavelength is $465 \mathrm{~nm}$.

\section{Measurements selected for analysis}

On 5 and 6 August 2010, the UAS flew a $210 \mathrm{~km}$ pattern designed such that one of the flight legs would be centered on the MODIS granule as close in time as possible to the MODIS overpass. The flight pattern flown is shown in Fig. 2. On 5 August the sky at Summit was overcast with some blue patches at takeoff. The cloud deck thickened during the flight to a uniform diffuse cover. This development is readily visible in the global shortwave measurements recorded at Summit (blue line, Fig. 4). The measured shortwave radiation is clearly below the cloudless simulated shortwave 


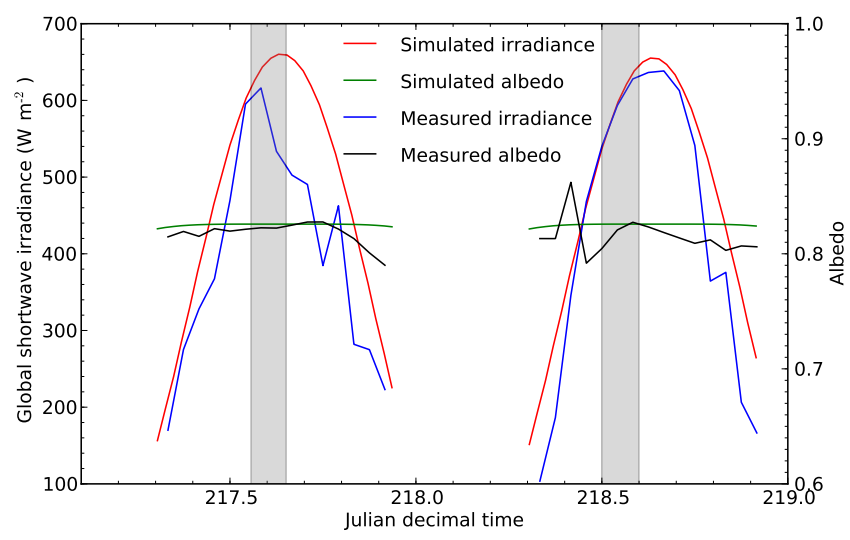

Figure 4. The measured (blue) and the simulated cloudless sky (red) downwelling shortwave radiation for Summit, Greenland, on $5 \mathrm{Au}-$ gust (day 217) and 6 August (day 218) 2010. The measured (black) and simulated (green) shortwave broadband albedos are also shown. The grey shaded areas indicate the time when the UAS was flying.

radiation, and its behavior indicates the presence of clouds. The wind was blowing from the southeast at speeds around 6-7 $\mathrm{m} \mathrm{s}^{-1}$ (Table 2). On 6 August the sky was mostly clear during most of the flight, with some thin layer cirrus forming at the end of the flight. The wind was more gentle on $6 \mathrm{Au}-$ gust, with speeds increasing from about 1.5 to $3.5 \mathrm{~m} \mathrm{~s}^{-1}$ during the flight. At the same time the wind direction changed from southeast to a more southerly direction.

The pitch and roll angles of the UAS had nonzero offsets, indicating that the aircraft was flying in a non-leveled manner due to impact of wind, fuel-load, and placement of the center of mass. The offsets varied between the various flights and are given in Table 2 . UAS data that are within $\pm 0.5^{\circ}$ of the mean pitch and roll angles were included in the analysis. Furthermore, due to the sensitivity of the measurements to the orientation of the uplooking instrument discussed above, only data for which the yaw angle was stable were included in the analysis. For 5 and 6 August the instrument azimuth (blue dots) and the corresponding tilt correction (red dots) are shown in Figs. 5a and 6a, respectively.

MODIS bands 1, 3, and 4 NBARs (see Sect. 5) were extracted from the MODIS pixels that coincide with the Cryowing UAS data points. The blue, green, and red MODIS NBARs are shown in the second, third, and fourth panels, respectively, of Figs. 5 and 6. Data that are flagged as high quality are in black, while lower-quality flagged MODIS data are in yellow.

\section{MODIS nadir NBAR measurements}

The MODIS NBAR product from MCD43 Collection 6 is used for intercomparison in this analysis. The MODIS instrument (Justice et al., 1998) measures radiance at the top of the atmosphere. These measurements must first be cloud-
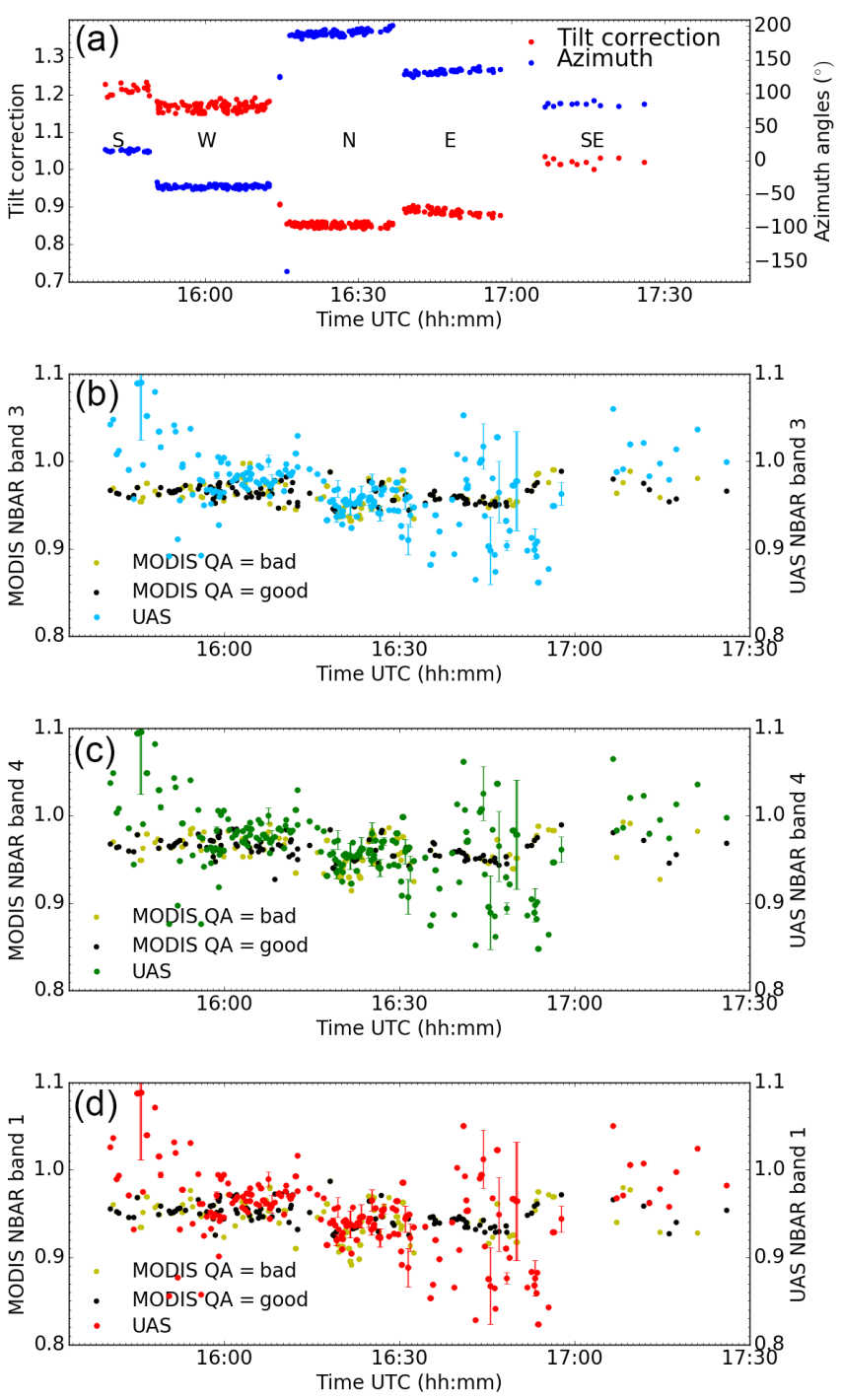

Figure 5. (a) The azimuth angle of the UAS (blue dots) and the tilt correction factor $R^{\mathrm{l}} / R^{\mathrm{t}}$, Eq. (3) (red dots). The various flight track elements are identified by letters and correspond to the flight tracks in Fig. 2. (b-d) The MODIS (black dots: good quality; yellow dots: low quality) and UAS band 3 (blue), 4 (green), and 1 (red) NBARs as a function of time. In the case of several UAS data points within one MODIS pixel, the UAS data have been grouped together and presented as a dot with standard deviation. All data from the flight on 5 August 2010.

cleared and atmospherically corrected, following which multiangle directional reflectances from both the Terra and Aqua MODIS sensors, over a period of 16 days, are accumulated for a location. From these directional reflectances, an appropriate RossThick LiSparse Reciprocal empirical kernelbased BRDF model is estimated. The MODIS BRDF/albedo product is widely used and has been described by Lucht et al. (2000), Schaaf et al. (2002), and Stroeve et al. (2005). The retrieved BRDF is then integrated over all view zenith angles to calculate an intrinsic directional hemispherical reflectance 

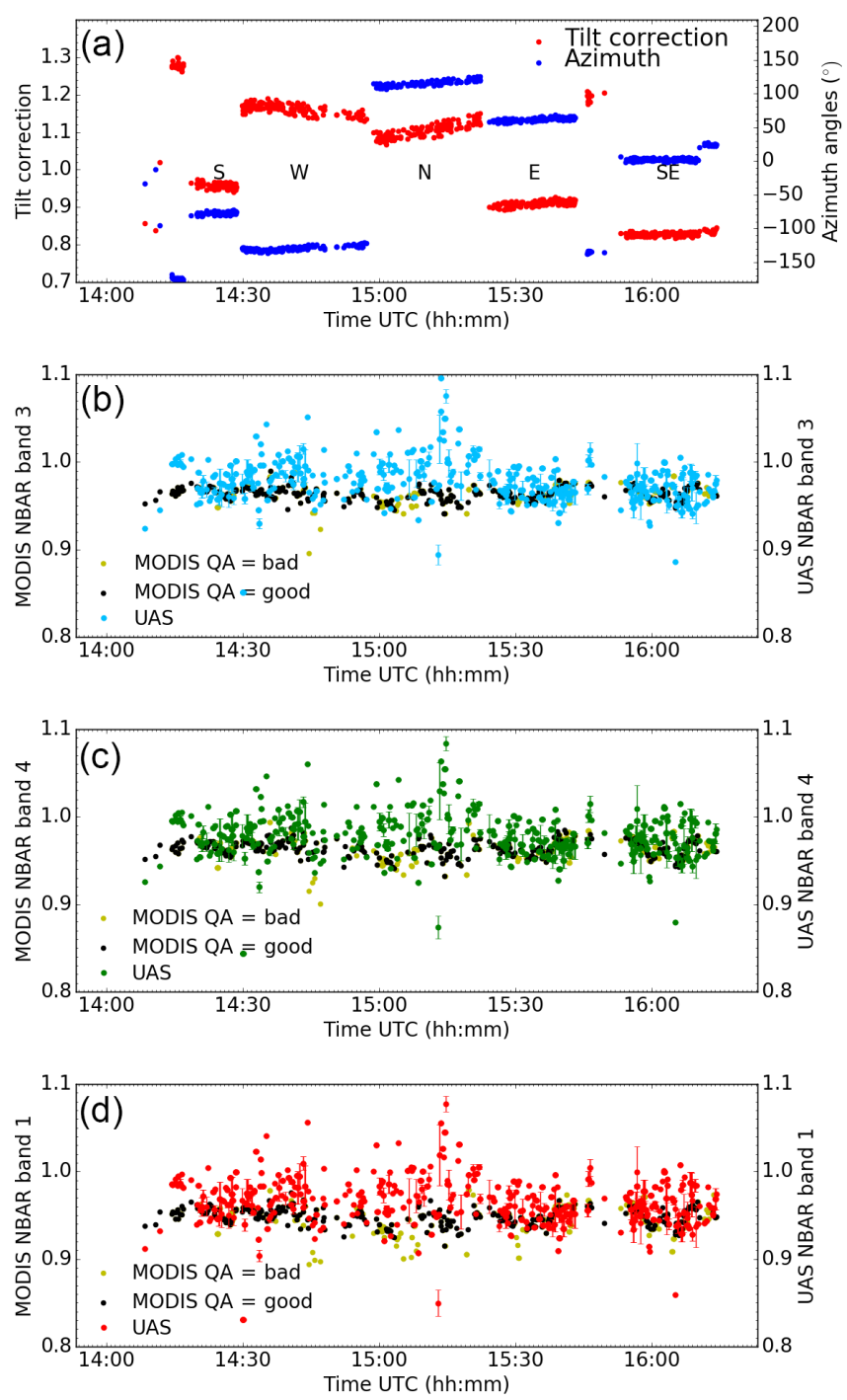

Figure 6. (a) The azimuth angle of the UAS (blue dots) and the tilt correction factor $R^{1} / R^{\mathrm{t}}$, Eq. (3) (red dots). The various flight track elements are identified by letters and correspond to the flight tracks in Fig. 2. (b-d) The MODIS (black dots: good quality; yellow dots: low quality) and UAS band 3 (blue), 4 (green), and 1 (red) NBARs as a function of time. In the case of several UAS data points within one MODIS pixel, the UAS data have been grouped together and presented as a dot with standard deviation. All data from the flight on 6 August 2010.

(a black-sky albedo) for the seven MODIS land bands. The BRDF model is further integrated over all possible illumination angles to produce a bihemispherical reflectance (or white-sky albedo). The latest reprocessed operational Collection 6 MODIS daily BRDF/albedo/NBAR products improve the temporal aggregation of snow observations (Wang et al., 2012, 2014) by using a daily measurement and triangulated filter to emphasize the nearest-day observations. The snow/non-snow status of the day of interest is utilized for retrievals in Collection 6 instead of the previous Collection 5 strategy of only capturing snow measurements when snow cover represented the majority situation over the 16-day retrieval period. Of the seven available, bands 3,4 , and 1 are used here.

\section{Discussion}

In the following we evaluate differences between the UASmeasured nadir reflectance and the MODIS NBAR product. Unless otherwise noted, the data refer to high-quality flagged Collection 6 of the MODIS daily NBAR product (MCD43). We also include data from Collection 5 to demonstrate some of the marked improvements as well as evaluate the importance of quality flagging.

The MODIS albedo product has been compared with in situ measurements in Greenland (e.g., Stroeve et al., 2005) and a number of other snow-covered locations (Wang et al., 2014). The root mean square error between MODIS and in situ measurements was within $\pm 0.04( \pm 0.07)$ for high-quality (poor-quality) flagged MODIS albedos. A highquality flag indicates that sufficiently high-quality surface reflectances to adequately sample the full angular hemisphere were acquired and that a high-quality full inversion BRDF model was able to be developed to produce NBAR and the intrinsic surface albedo quantities. For poor-quality flagged retrievals a BRDF model could not be retrieved, and a backup algorithm with a predetermined BRDF for that location had to be utilized. These intrinsic surface quantities are related to the surface structure, and the albedos represent fully direct and fully diffuse values. Critically, the direct and diffuse values need to be combined as a function of optical thickness to simulate the blue-sky albedos routinely captured with albedometers at surface tower locations (Lucht et al., 2000; Schaaf et al., 2002; Román et al., 2010). In order to incorporate the full atmospheric effects, the full multiple scattering of the Román et al. (2010) formation needs to be used over snow surfaces. While these analyses have been clearly valuable to the community, the intercomparison is complicated due to the nature of the measurement-model chain required to derive albedo. We reduce, by at least one degree, the required modeling for the comparison by evaluating NBAR, which both platforms measure directly, rather than albedo, which must be derived.

In general the agreement between the UAS nadir reflectance and MODIS NBARs is within the measurement uncertainties (Figs. 5 and 6). Systematically, the UAS measurements are higher than those of the MODIS NBARs, albeit well within $3 \%$ of each other. The mean NBAR values for each flight are provided in Table 1. Percentage differences based on the mean value of the platforms show that on $5 \mathrm{Au}-$ gust the differences between the UAS and MODIS data were within $1 \%$, despite greater variability on this day. On $6 \mathrm{Au}-$ gust the differences were greater, while still less than $2 \%$. As expected from the refractive index of ice and NBAR calcu- 
Table 1. Mean NBAR values from MODIS and the UAS on 5 and 6 August for bands 3, 4, and 1. Percentage differences are calculated based on the mean of the two values.

\begin{tabular}{cccccccc}
\hline \multirow{2}{*}{ Band } & \multicolumn{3}{c}{5 August } & & \multicolumn{3}{c}{ 6 August } \\
\cline { 2 - 4 } \cline { 6 - 8 } & UAS & MODIS & $\%$ & & UAS & MODIS & $\%$ \\
\hline 3 & 0.971 & 0.967 & 0.41 & & 0.978 & 0.965 & 1.34 \\
4 & 0.974 & 0.966 & 0.83 & & 0.980 & 0.965 & 1.54 \\
1 & 0.956 & 0.952 & 0.42 & & 0.967 & 0.950 & 1.77 \\
\hline
\end{tabular}

lations (see Fig. 1), there is little wavelength dependence in the NBARs of bands 3 and 4, whereas there is an expected decrease in NBAR for band 1.

In Table 2 we also include a summary of the MODIS Collection 5 data, which are only retrieved once every 8 days and not filtered to weight the day of interest. The agreement between the UAS and MODIS version 6 is better than between the UAS and MODIS version 5 for bands 3 and 1 . For band 4 there is better agreement between the UAS and MODIS version 5. However, the differences are within the uncertainties; see below. Further, the standard deviation is generally smaller for the version 6 data.

Variability in the measurements reflects the conditions at time of acquisition. Consistently, the standard deviations for all products are slightly larger for the flight on 5 August due to the more turbid atmospheric conditions. The variability is a product not only of the cloud cover but also of the wind speed, which potentially increased turbulence for the aircraft. We further see strong support for the quality flagging of the MODIS products. The variations of the MODIS NBARs are larger for the pixels identified as low-quality retrievals than for the good-quality retrievals (see standard deviations in parentheses in Table 2).

The UAS measures the instantaneous upwelling radiance within $7^{\circ}$ and the full-hemisphere downwelling irradiance, with the ratio of the two providing the reflectance, whereas the radiances measured by MODIS at the top of the atmosphere are atmospherically corrected to surface reflectance by means of radiative transfer modeling. These directional surface reflectances at a location - time weighted to the day of interest - are gathered over a 16-day period from both Terra and Aqua, and used to derive the BRDF for the full range of solar and viewing angles. The BRDF is then used to calculate an NBAR or an albedo for the seven MODIS bands. Here we have used the BRDF to calculate a solarnoon nadir reflectance for comparison with the UAS. Hence, it is important to recognize the MODIS products are not instantaneous nadir reflectance measurements but rather a calculation guided by data acquisition. Given the difference between the derived MODIS data product and instantaneous UAS measurement, the correspondence is impressive. The standard deviation in the UAS data varies between 0.025 and 0.065. The standard deviation in high (low)-quality MODIS data varies from $0.008(0.009)$ to $0.015(0.024)$. Given the smaller footprint, instabilities in the platform, and uncertainties related to the snow surface roughness, it is expected for the UAS-derived reflectances to have higher standard deviation. Further, as these data are instantaneous measurements rather than an integrated model product, one should expect greater variance. This greater variance and sub-pixel variability potentially contribute to the fact that, despite more stable flight conditions on 6 August, the difference between the two platforms is slightly greater (cf. Table 1).

The footprint of the MODIS reflectance shown in this study is $500 \mathrm{~m}^{2}$ at nadir but has an effective footprint of $833 \mathrm{~m} \times 613 \mathrm{~m}$ at the latitudes of this study (Campagnolo et al., 2016). The footprint of the UAS is circular with a diameter of about $30 \mathrm{~m}$. Thus the UAS may be used to investigate MODIS sub-pixel variability. Where several UAS measurements are available within a pixel, there is considerable variability within a MODIS pixels; see data points with error bars in Figs. 5 and 6. However, this variability is within the uncertainty in the UAS data. Given more stable flight conditions, measurement of MODIS sub-pixel variability should be fully feasible with a UAS.

Optical satellite instruments require cloud-free conditions to make NBAR estimates. This clearly limits the number of days available for NBAR measurements. The UAS is not limited to a cloud-free sky but may be used to measure nadir reflectance also under cloudy conditions. However, as discussed below, the UAS must be below the cloud layer and not in it or a haze layer.

In Fig. 7 we evaluate the differences between Collection 5 and 6 MODIS products. Two distinct features stand out. First, there is an improvement in the poorer-quality magnitude estimates in Collection 6 as demonstrated by the systematic shift leftward of the data cluster from Collection 5 to 6 . Most data fall below a reflectance of 1.0, whereas in Collection 5 several values were greater than 1 . We note a value of greater than 1 is not impossible, and in fact quite apparent for the UAS data, likely resulting from forward scattering driven by the sustruggi and expected at the scale of these measurements (30 m footprint). For the MODIS data, however, covering a square kilometer $\left(\mathrm{km}^{2}\right)$ footprint, one would expect reflectances to be more smoothed, and values greater than 1 are expectedly rare. The second feature is a clear decrease in the variability of the data, both in terms of the overall spread and for the flagged values. There are fewer poor-quality retrievals in Collection 6, resulting from the improved temporal retrieval frequency in the algorithm.

Regarding the quality and no data flagging, we find the differences noted between 5 and 6 August clearly important (Fig. 8). The flight conditions were better (fewer clouds) on 6 August, and more MODIS data points have a good retrieval flag. Nevertheless the data points flagged as low quality have a spatial variation in agreement with the good-quality points; compare yellow (low) and black (good) dots in Figs. 5 and 6 and the scatterplots shown in Fig. 7. Particularly for Collec- 
MODIS Band:

Band 3

5 Aug.

MOD V.005

MOD V.006

6 Aug.

MOD V.005

MOD V.006
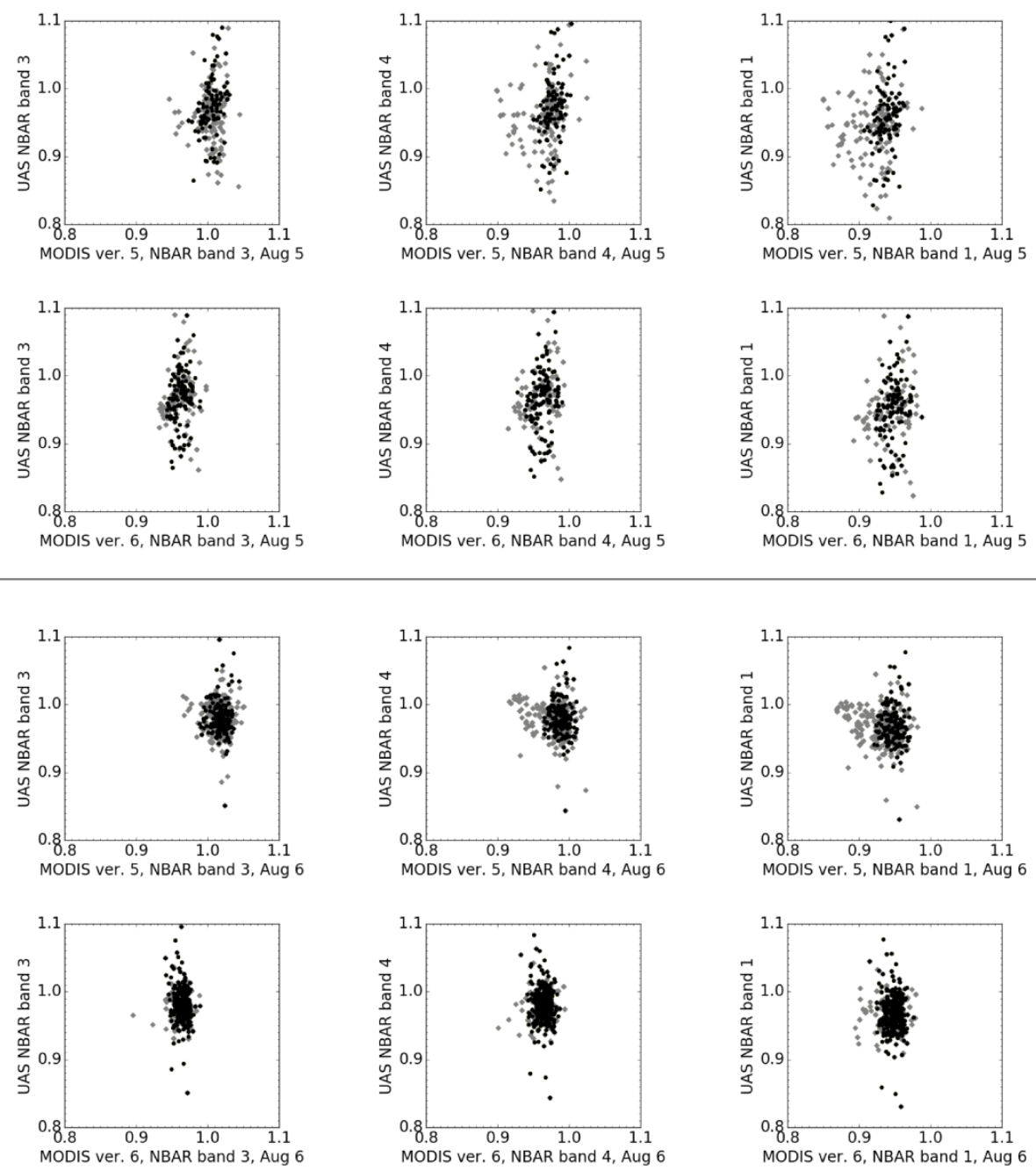

Figure 7. The MODIS (black: high quality; grey: low quality) versus UAS NBAR for bands 3, 4, and 1. Left column is data for band 3 , middle column is data for band 4, and right column is data for band 1. Rows 1 and 3 are MODIS version 5, and rows 2 and 4 are MODIS version 6. Rows 1-2 (3-4) are data from the flight on 5 (6) August.
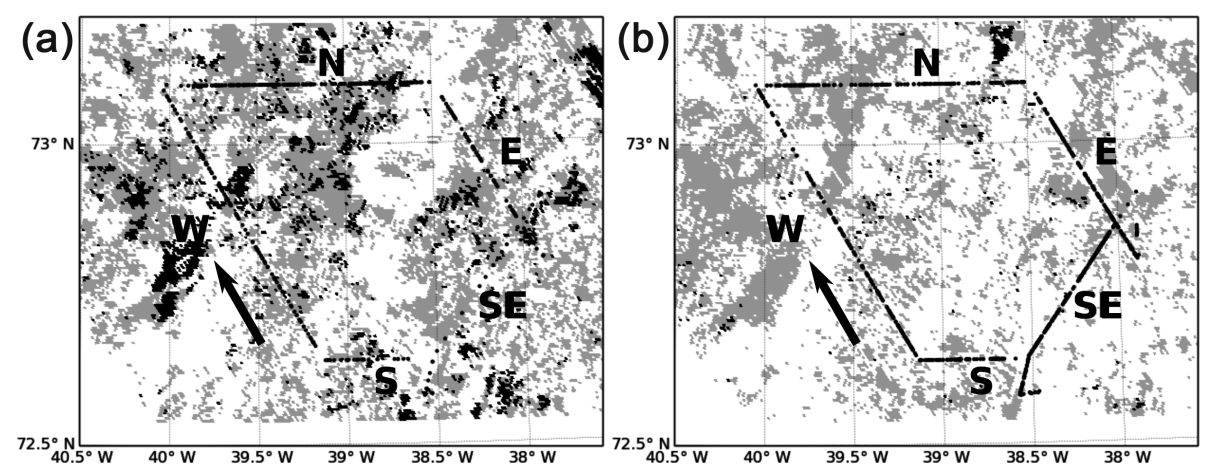

Figure 8. MODIS quality flags for 5 August (a) and 6 August (b) 2010. Grey color indicates low-quality retrieval; black indicates no retrieval. White areas have high-quality retrieval flags. Flight transects are as labeled in Figs. 5 and 6 . The arrow indicates direction of flight. Flights started with the $\mathrm{S}$ transect and were flown clockwise. 
Table 2. Information for the two UAS MODIS route overpass flights. For the NBAR values the average value is given together with the standard deviation in parentheses.

\begin{tabular}{|c|c|c|c|c|}
\hline & \multicolumn{2}{|c|}{5 August } & \multicolumn{2}{|c|}{6 August } \\
\hline Start of flight (hh:mm:ss, UTC) & \multicolumn{2}{|c|}{$15: 22: 55$} & \multicolumn{2}{|c|}{$14: 00: 28$} \\
\hline End of flight (hh:mm:ss, UTC) & \multicolumn{2}{|c|}{$17: 37: 27$} & \multicolumn{2}{|c|}{$16: 23: 34$} \\
\hline Mean pitch $(\mathrm{SD})$ angle $\left(^{\circ}\right)$ & \multicolumn{2}{|c|}{$6.05(0.55)$} & \multicolumn{2}{|c|}{$7.32(0.52)$} \\
\hline Mean roll (SD) angle $\left(^{\circ}\right)$ & \multicolumn{2}{|c|}{$-4.43(0.48)$} & \multicolumn{2}{|c|}{$5.40(0.54)$} \\
\hline Weather & \multicolumn{2}{|c|}{ Overcast } & \multicolumn{2}{|c|}{ Mostly cloudless } \\
\hline Solar zenith angle $\left(^{\circ}\right)$ & \multicolumn{2}{|c|}{$60-56$} & \multicolumn{2}{|c|}{$55-58$} \\
\hline Solar azimuth angle $\left({ }^{\circ}\right)$ & \multicolumn{2}{|c|}{-46 to -17} & \multicolumn{2}{|c|}{11 to -27} \\
\hline Wind speed $\left(\mathrm{ms}^{-1}\right)$ & \multicolumn{2}{|c|}{$6-7$} & \multicolumn{2}{|c|}{$1.5-3.5$} \\
\hline Wind direction $\left(^{\circ}\right)$ & \multicolumn{2}{|c|}{$\approx 135$} & \multicolumn{2}{|c|}{$140-170$} \\
\hline \# UAS spectra & \multicolumn{2}{|c|}{497} & \multicolumn{2}{|c|}{882} \\
\hline MODIS quality flag & 0 (Good) & 1 (Low) & 0 (Good) & 1 (Low) \\
\hline MODIS ver 5, NBAR band 3 (blue) & $1.005(0.012)$ & $1.005(0.015)$ & $1.017(0.011)$ & $1.017(0.012)$ \\
\hline MODIS ver 6 , NBAR band 3 (blue) & $0.967(0.010)$ & $0.965(0.014)$ & $0.965(0.008)$ & $0.966(0.009)$ \\
\hline UAS band 3 & \multicolumn{2}{|c|}{$0.971(0.056)$} & \multicolumn{2}{|c|}{$0.978(0.025)$} \\
\hline MODIS ver 5 , NBAR band 4 (green) & $0.978(0.011)$ & $0.967(0.024)$ & $0.988(0.010)$ & $0.982(0.019)$ \\
\hline MODIS ver 6 , NBAR band 4 (green) & $0.966(0.013)$ & $0.964(0.016)$ & $0.965(0.009)$ & $0.965(0.012)$ \\
\hline UAS band 4 & \multicolumn{2}{|c|}{$0.974(0.064)$} & \multicolumn{2}{|c|}{$0.980(0.026)$} \\
\hline MODIS ver 5, NBAR band 1 (red) & $0.939(0.0123)$ & $0.956(0.027)$ & $0.948(0.011)$ & $0.937(0.022)$ \\
\hline MODIS ver 6, NBAR band 1 (red) & $0.952(0.0146)$ & $0.947(0.020)$ & $0.950(0.010)$ & $0.949(0.014)$ \\
\hline UAS band 1 & \multicolumn{2}{|c|}{$0.956(0.065)$} & \multicolumn{2}{|c|}{$0.967(0.028)$} \\
\hline
\end{tabular}

tion 5, there is larger variation in the low-quality MODIS data, yet there is no support for this variation in UAS measurements. Thus overall, the MODIS algorithm appears to correctly discriminate good- and low-quality data.

We note significantly greater variability in the 5 August flight data. This is to be anticipated given the sky conditions, but the data provide a valuable reference for comparison with the MODIS data. Some features stand out from the flight, the first being what appears to be a consistent decrease in reflectance from the start of the flight until 17:00 UTC, when the flight initiates the SE leg. Overall the reflectance decreases in this period by almost $10 \%$. The flight on $6 \mathrm{Au}-$ gust followed the same flight pattern, but no such drop in reflectance is present. There are several plausible explanations for the drop, including a drop in surface reflectance, measurement error, or presence of slightly absorbing particles in the atmosphere. As the drop was only seen on 5 August and not on the subsequent day, and, further, the drop is not seen in the good-quality MODIS data, we therefore rule out a change in the surface reflectance. The drop could be due to incorrect tilt correction. However we investigated this thoroughly and find no feasible explanation why this error would be introduced on the 5 August flight but not on the 6 August flight. Additionally, as the drop occurred continuously through multiple legs and is then not seen at the end of the flight, we also rule out this explanation.
From Fig. 4 it is evident that some clouds were present during part of the flight on 5 August. While these could have an impact on reflectance due to shadowing, a non-absorbing cloud will not change the surface reflectance as measured by the UAS. On the other hand, if the UAS encounters an optically thin, slightly absorbing haze layer, the UAS measured reflectance will drop. To quantify this drop, radiative transfer calculations were made of the UAS reflectance with the UAS being at different flight altitudes. Cloudless and various haze conditions were considered. As shown in Fig. 9, the reflectance on a cloudless day (red line) does not depend on the altitude of the UAS. If an optically thin (optical depth: 0.5) and slightly absorbing (single-scattering albedo: 0.95) haze layer of $1 \mathrm{~km}$ vertical thickness is included, the UAS measured reflectance will be lower than the surface reflectance (green line), and the difference will increase with increasing altitude.

The haze layer optical property values used are representative for those reported for Arctic haze (cf. Tsay et al., 1989; Hess et al., 1998; Quinn et al., 2007). Increasing the absorption (single-scattering albedo: 0.9) increases the difference even more (dash-dot line). The average flight altitude of UAS on 5 August is indicated by the horizontal dotted line in Fig. 9. The drop seen in the UAS reflectance on 5 August may thus be explained by the UAS entering an optically thin and slightly absorbing haze layer. However, due to a lack of additional measurements (aerosol properties) we can not prove 


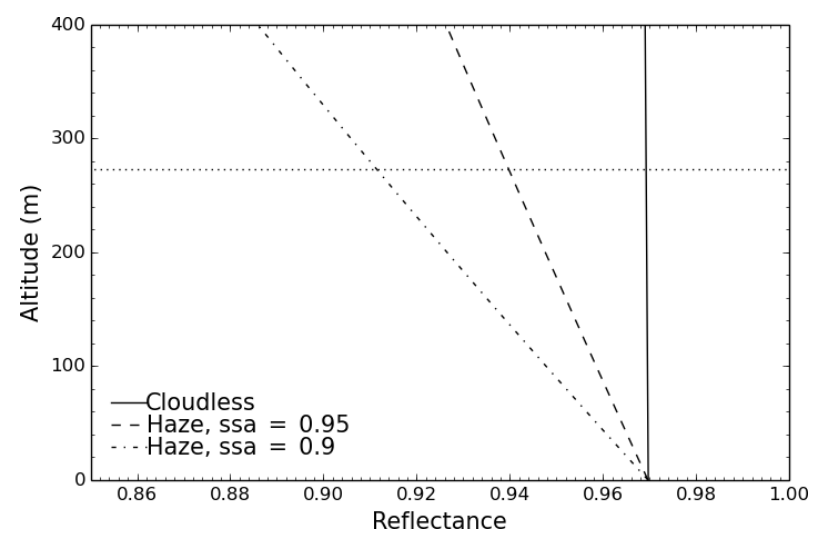

Figure 9. Simulated UAS reflectance for MODIS band 1 as a function of flight altitude for various sky conditions. See text for details. The dotted horizontal line indicates the average flight altitude of the UAS on 5 August. The solar zenith angle is $58^{\circ}$, corresponding to the values during the flight on 5 August (see Table 2).

this. But it is noted that during haze conditions reflectance measured by an airborne platform may be affected by the atmosphere between the platform and the surface. An ideal platform for surface reflectance observations would include aerosol observations such as those presented in Bates et al. (2013).

Covering the same flight path on 6 August, the UAS data and MODIS products agree remarkably well. As mentioned earlier, we note greater variability in the UAS data resulting from several factors. For one, the UAS is measuring a smaller area, and thus there is far less smoothing of the data. Certainly surface roughness and forward scattering play a role, but despite best efforts to select only stable periods of flight, there is likely error introduced to the data from platform stability. Nonetheless, the consistent feature is that the UAS values are systematically larger than the MODIS products (Table 1). Given the nature and temporal smoothing of the MODIS products, we believe this is a real artifact and that the MODIS data may in fact provide values slightly lower than actual reflectances that would be observed instantaneously. We also note that the UAS platform has immense potential to provide greater insight into the sub-pixel variability of the MODIS products - which is likely significant.

\section{Conclusions}

During July-August 2010, several UAS flights were made over Summit, Greenland. Two of the flights were designed to cover the MODIS swath and were made close in time to the MODIS overpass. The UAS measured the up- and downwelling radiation between 320 and $950 \mathrm{~nm}$ with a resolution of $3.3 \mathrm{~nm}$. In this analysis we have made a direct comparison of reflectance as measured by the UAS with the MODIS NBAR product. The main findings are as follows:
- The UAS and MODIS reflectances for bands 3, 4, and 1 agree within their uncertainties. However, due to the larger footprint and temporal smoothing of MODIS, the product provides a slightly lower overall reflectance.

- Sub-pixel variability of MODIS reflectance products is potentially significant. Further work should be conducted to evaluate the magnitude and consequent impacts on modeling of greater variability at the subkilometer scale.

- Consistent with theory, the UAS and MODIS reflectance measurements show a decrease between bands 3 and 4 and band 1 . This wavelength dependence agrees with that expected from the refractive index of ice.

- Even at the low elevations flown typically by a UAS, reflectance measurements may be influenced by haze if present at and/or below the flight altitude of the UAS.

- The UAS platform is proven as a capable resource to collect reflectance measurements over an extensive region and provides a reliable resource for evaluating spatial variability of reflectance for Summit, Greenland, and the surrounding area.

Of significance in this evaluation, and any intercomparison, is the concept of "truth". Neither of the platforms presented provide a perfect measure of NBAR, but this is a much more direct intercomparison than would be with albedo, which would require several further assumptions. MODIS and the UAS platforms attempt to provide an accurate characterization of NBAR and nadir reflectance, respectively. However, MODIS, while collecting direct radiance measurements, requires a model and data assimilation chain to provide a product - ultimately produced from a BRDF model. The UAS is challenged due to platform instabilities and expected instrumental errors. The nature of reflectance observations is further challenged by the fact that it is not a simple property of a surface (e.g., snow), but rather a product of a system. The system includes not only many temporally varying factors such as solar zenith angle and azimuth but also more dynamic processes including atmospheric scattering, surface roughness, and snow conditions. The timescales of variability of these processes differ and are not trivial to represent consistently. Given the importance of this parameter and the general derivation of albedo from these observations, it is critical that we understand well the expected variability. The UAS platform provides a unique opportunity to collect observations that are more representative spatially for applications where point-based measurements are used, for instance, the validation of satellite-based remotely sensed measurements and "grid"-based climate and earth system models. This work not only demonstrates the feasibility of collecting these observations but also exemplifies the 
challenges associated with benchmarking different observations. Furthermore, the observations presented herein were collected over a range offering relatively low variability in reflectance. To further increase our current understanding of the reflectance of the cryosphere and its development, more UAS measurement campaigns at other locations and surface conditions are warranted.

Data availability. MODIS data are available from http://modis. gsfc.nasa.gov/. Surface irradiance data for Summit, Greenland, are available from https://nsidc.org/. The UAS data are available from NORSTORE: https://archive.norstore.no/pages/public/ datasetDetail.jsf?id=10.11582/2017.00005.

Competing interests. The authors declare that they have no conflict of interest.

Acknowledgements. This work was conducted within the Norwegian Research Council's NORKLIMA program under the Variability of Albedo Using Unmanned Aerial Vehicles (VAUUAV; NFR no. 184724) and Hydrologic sensitivity to Cryosphere-Aerosol interaction in Mountain Processes (HyCAMP; NFR no. 222195) projects, and with additional support from NFR no. 196204 (RISCC) and NFR no. 195143 (Arctic-EO). Computational and data storage resources were provided by NOTUR/NORSTORE projects NS9333K and NN9333K. Data processing was conducted with open-source Python tools, namely numpy (Ascher et al., 1999) and xarray (Hoyer and Hamman, 2017). We acknowledge the Greenland Home Rule Government for permission to work in Greenland; the 109th Airlift Wing of the New York Air National Guard (NY ANG) for unsurpassed air transport; $\mathrm{CH} 2 \mathrm{M}$ HILL Polar Services and the on-site science technicians for superb logistical support; the GEOSummit Science Coordination Office (SCO, PLR-1042531) for providing contacts and access to data; and overall the support from the Division of Polar Programs at the National Science Foundation. Konrad Steffen provided the shortwave radiation data from Summit, while NOAA-ESRL (Brian Vasel and Tom Mefford) provided wind speed and direction.

Edited by: Edward Hanna

Reviewed by: two anonymous referees

\section{References}

Anderson, G. P., Clough, S. A., Kneizys, F. X., Chetwynd, J. H., and Shettle, E. P.: AFGL Atmospheric Constituent Profiles $(0.120 \mathrm{~km})$ Environmental research papers, Accession Number: ADA175173, AIR FORCE GEOPHYSICS LAB HANSCOM AFB MA, Defense Technical Information Center, available at: http://www.dtic.mil/docs/citations/ADA175173 (last access: 28 June 2017), 1986.

Ascher, D., Dubois, P. F., Hinsen, K., Hugunin, J., and Oliphant, T.: Numerical Python, Lawrence Livermore National Laboratory, Livermore, CA, ucrl-ma-128569 Edn., 1999.
Bais, A. F., Kazadzis, S., Balis, D., Zerefos, C. S., and Blumthaler, M.: Correcting Global Solar Ultraviolet Spectra Recorded by a Brewer Spectroradiometer for its Angular Response Error, Appl. Optics, 37, 6339, https://doi.org/10.1364/AO.37.006339, 1998.

Bates, T. S., Quinn, P. K., Johnson, J. E., Corless, A., Brechtel, F. J., Stalin, S. E., Meinig, C., and Burkhart, J. F.: Measurements of atmospheric aerosol vertical distributions above Svalbard, Norway, using unmanned aerial systems (UAS), Atmos. Meas. Tech., 6, 2115-2120, https://doi.org/10.5194/amt-6-2115-2013, 2013.

Bennartz, R., Shupe, M. D., Turner, D. D., Walden, V. P., Steffen, K., Cox, C. J., Kulie, M. S., Miller, N. B., and Pettersen, C.: July 2012 Greenland melt extent enhanced by low-level liquid clouds, Nature, 496, 83-86, https://doi.org/10.1038/nature12002, 2013.

Bhardwaj, A., Sam, L., Akanksha, Martín-Torres, F. J., and Kumar, R.: UAVs as remote sensing platform in glaciology: Present applications and future prospects, Remote Sens. Environ., 175, 196-204, https://doi.org/10.1016/j.rse.2015.12.029, 2016.

Bogren, W. S., Burkhart, J. F., and Kylling, A.: Tilt error in cryospheric surface radiation measurements at high latitudes: a model study, The Cryosphere, 10, 613-622, https://doi.org/10.5194/tc-10-613-2016, 2016.

Box, J. E., Fettweis, X., Stroeve, J. C., Tedesco, M., Hall, D. K., and Steffen, K.: Greenland ice sheet albedo feedback: thermodynamics and atmospheric drivers, The Cryosphere, 6, 821-839, https://doi.org/10.5194/tc-6-821-2012, 2012.

Buras, R., Dowling, T., and Emde, C.: New secondary-scattering correction in DISORT with increased efficiency for forward scattering, J. Quant. Spectrosc. Ra., 112, 2028-2034, https://doi.org/10.1016/j.jqsrt.2011.03.019, 2011.

Campagnolo, M. L., Sun, Q., Liu, Y., Schaaf, C., Wang, Z., and Román, M. O.: Estimating the effective spatial resolution of the operational BRDF, albedo, and nadir reflectance products from MODIS and VIIRS, Remote Sens. Environ., 175, 52-64, https://doi.org/10.1016/j.rse.2015.12.033, 2016.

Curry, J. and Schramm, J.: Applications of SHEBA/FIRE data to evaluation of snow/ice albedo parameterizations, J. Geophys. Res., 106, 15345-15355, https://doi.org/10.1029/2000JD900311, 2001.

Dumont, M., Brun, E., Picard, G., Michou, M., Libois, Q., Petit, J.-R., Geyer, M., Morin, S., and Josse, B.: Contribution of light-absorbing impurities in snow to Greenland's darkening since 2009, Nat. Geosci., 7, 509-512, https://doi.org/10.1038/NGEO2180, 2014.

Emde, C., Buras-Schnell, R., Kylling, A., Mayer, B., Gasteiger, J., Hamann, U., Kylling, J., Richter, B., Pause, C., Dowling, T., and Bugliaro, L.: The libRadtran software package for radiative transfer calculations (version 2.0.1), Geosci. Model Dev., 9, 1647-1672, https://doi.org/10.5194/gmd-9-1647-2016, 2016.

Flanner, M. G., Zender, C. S., Hess, P. G., Mahowald, N. M., Painter, T. H., Ramanathan, V., and Rasch, P. J.: Springtime warming and reduced snow cover from carbonaceous particles, Atmos. Chem. Phys., 9, 2481-2497, https://doi.org/10.5194/acp9-2481-2009, 2009.

Goelles, T., Bøggild, C. E., and Greve, R.: Ice sheet mass loss caused by dust and black carbon accumulation, The Cryosphere, 9, 1845-1856, https://doi.org/10.5194/tc-9-1845-2015, 2015.

Hakala, T., Riihelä, A., Lahtinen, P., and Peltoniemi, J. I.: Hemispherical-directional reflectance factor measurements of snow on the Greenland Ice Sheet during the Radia- 
tion, Snow Characteristics and Albedo at Summit (RASCALS) campaign, J. Quant. Spectrosc. Ra., 146, 280-289, https://doi.org/10.1016/j.jqsrt.2014.04.010, 2014.

Hansen, J. and Nazarenko, L.: Soot climate forcing via snow and ice albedos, P. Natl. Acad. Sci. USA, 101, 423-428, https://doi.org/10.1073/pnas.2237157100, 2004.

Henderson-Sellers, A. and Wilson, M.: Surface Albedo Data for Climatic Modeling, Rev. Geophys., 21, 1743-1778, https://doi.org/10.1029/RG021i008p01743, 1983.

Hess, M., Koepke, P., and Schult, I.: Optical properties of aerosols and clouds: The software package OPAC, B. Am. Meteorol. Soc., 79, 831-844, 1998.

Howat, I. M., Negrete, A., and Smith, B. E.: The Greenland Ice Mapping Project (GIMP) land classification and surface elevation data sets, The Cryosphere, 8, 1509-1518, https://doi.org/10.5194/tc-8-1509-2014, 2014.

Hoyer, S. and Hamman, J.: xarray: N-D labeled arrays and datasets in Python, Journal of Open Research Software, 5, 10, https://doi.org/10.5334/jors.148, 2017.

Immerzeel, W., Kraaijenbrink, P., Shea, J., Shrestha, A., Pellicciotti, F., Bierkens, M., and de Jong, S.: Highresolution monitoring of Himalayan glacier dynamics using unmanned aerial vehicles, Remote Sens. Environ., 150, 93-103, https://doi.org/10.1016/j.rse.2014.04.025, 2014.

IPCC: Climate Change 2013: The Physical Science Basis. Contribution of Working Group I to the Fifth Assessment Report of the Intergovernmental Panel on Climate Change, edited by: Stocker, T. F., Qin, D., Plattner, G.-K., Tignor, M., Allen, S. K., Boschung, J., Nauels, A., Xia, Y., Bex, V., and Midgley, P. M., Cambridge University Press, Cambridge, United Kingdom and New York, NY, USA, 1535 pp., 2013.

Jagt, B., Lucieer, A., Wallace, L., Turner, D., and Durand, M.: Snow Depth Retrieval with UAS Using Photogrammetric Techniques, Geosciences, 5, 264-285, https://doi.org/10.3390/geosciences5030264, 2015.

Jin, Y.: Consistency of MODIS surface bidirectional reflectance distribution function and albedo retrievals: 2. Validation, J. Geophys. Res., 108, 1-15, https://doi.org/10.1029/2002JD002804, 2003.

Ju, J., Roy, D. P., Shuai, Y., and Schaaf, C.: Remote Sensing of Environment Development of an approach for generation of temporally complete daily nadir MODIS reflectance time series, Remote Sens. Environ., 114, 1-20, https://doi.org/10.1016/j.rse.2009.05.022, 2010.

Justice, C. O., Vermote, E., Townshend, J. R. G., Defries, R., Roy, D. P., Hall, D. K., Salomonson, V. V., Privette, J. L., Riggs, G., Strahler, A., Lucht, W., Myneni, R. B., Knyazikhin, Y., Running, S. W., Nemani, R. R., Wan, Z., Huete, A. R., van Leeuwen, W., Wolfe, R. E., Giglio, L., Muller, J., Lewis, P., and Barnsley, M. J.: The Moderate Resolution Imaging Spectroradiometer (MODIS): land remote sensing for global change research, IEEE T. Geosci. Remote, 36, 1228-1249, https://doi.org/10.1109/36.701075, 1998.

Keegan, K. M., Albert, M. R., McConnell, J. R., and Baker, I.: Climate change and forest fires synergistically drive widespread melt events of the Greenland Ice Sheet, P. Natl. Acad. Sci. USA, 111, 7964-7967, https://doi.org/10.1073/pnas.1405397111, 2014.
Lucht, W., Schaaf, C. B., and Strahler, A. H.: An algorithm for the retrieval of albedo from space using semiempirical BRDF models, IEEE T. Geosci. Remote, 38, 977-998, https://doi.org/10.1109/36.841980, 2000.

Mayer, B. and Kylling, A.: Technical note: The libRadtran software package for radiative transfer calculations - description and examples of use, Atmos. Chem. Phys., 5, 1855-1877, https://doi.org/10.5194/acp-5-1855-2005, 2005.

Miller, N. B., Shupe, M. D., Cox, C. J., Walden, V. P., Turner, D. D., and Steffen, K.: Cloud Radiative Forcing at Summit, Greenland, J. Climate, 28, 6267-6280, https://doi.org/10.1175/JCLI-D-150076.1, 2015.

Nicolaus, M., Hudson, S. R., Gerland, S., and Munderloh, K.: A modern concept for autonomous and continuous measurements of spectral albedo and transmittance of sea ice, Cold Reg. Sci. Technol., 62, 14-28, https://doi.org/10.1016/j.coldregions.2010.03.001, 2010.

Pierluissi, J. H. and Peng, G.-S.: New Molecular Transmission Band Models For LOWTRAN, Opt. Eng., 24, 243541, https://doi.org/10.1117/12.7973523, 1985.

Quinn, P. K., Shaw, G., Andrews, E., Dutton, E. G., Ruoho-Airola, T., and Gong, S. L.: Arctic haze: current trends and knowledge gaps, Tellus B, 59, 99-114, https://doi.org/10.1111/j.16000889.2006.00238.x, 2007.

Ricchiazzi, P., Yang, S., Gautier, C., and Sowle, D.: SBDART: A Research and Teaching Software Tool for Plane-Parallel Radiative Transfer in the Earth's Atmosphere, B. Am. Meteorol. Soc., 79, 2101-2114, 1998.

Rippin, D. M., Pomfret, A., and King, N.: High resolution mapping of supra-glacial drainage pathways reveals link between micro-channel drainage density, surface roughness and surface reflectance, Earth Surf. Proc. Land., 40, 1279-1290, https://doi.org/10.1002/esp.3719, 2015.

Román, M. O., Schaaf, C. B., Woodcock, C. E., Strahler, A. H., Yang, X., Braswell, R. H., Curtis, P. S., Davis, K. J., Dragoni, D., Goulden, M. L., Gu, L., Hollinger, D. Y., Kolb, T. E., Meyers, T. P., Munger, J. W., Privette, J. L., Richardson, A. D., Wilson, T. B., and Wofsy, S. C.: Remote Sensing of Environment The MODIS (Collection V005) BRDF/albedo product: Assessment of spatial representativeness over forested landscapes, Remote Sens. Environ., 113, 24762498, https://doi.org/10.1016/j.rse.2009.07.009, 2009.

Román, M. O., Schaaf, C. B., Lewis, P., Gao, F., Anderson, G. P., Privette, J. L., Strahler, A. H., Woodcock, C. E., and Barnsley, M.: Assessing the coupling between surface albedo derived from MODIS and the fraction of diffuse skylight over spatiallycharacterized landscapes, Remote Sens. Environ., 114, 738-760, https://doi.org/10.1016/j.rse.2009.11.014, 2010.

Ryan, J. C., Hubbard, A. L., Box, J. E., Todd, J., Christoffersen, P., Carr, J. R., Holt, T. O., and Snooke, N.: UAV photogrammetry and structure from motion to assess calving dynamics at Store Glacier, a large outlet draining the Greenland ice sheet, The Cryosphere, 9, 1-11, https://doi.org/10.5194/tc-9-1-2015, 2015.

Ryan, J. C., Hubbard, A., Box, J. E., Brough, S., Cameron, K., Cook, J. M., Cooper, M., Doyle, S. H., Edwards, A., Holt, T., Irvine-Fynn, T., Jones, C., Pitcher, L. H., Rennermalm, A. K., Smith, L. C., Stibal, M., and Snooke, N.: Derivation of High Spatial Resolution Albedo from UAV Digital Imagery: Application 
over the Greenland Ice Sheet, Frontiers in Earth Science, 5, 40, https://doi.org/10.3389/feart.2017.00040, 2017.

Salomonson, V. V. and Marlatt, W.: Airborne Measurements of Reflected Solar Radiation, Remote Sens. Environ., 2, 1-8, https://doi.org/10.1016/0034-4257(71)90072-1, 1971.

Schaaf, C. B., Gao, F., Strahler, A. H., Lucht, W., Li, X., Tsang, T., Strugnell, N. C., Zhang, X., Jin, Y., Muller, J.-P., Lewis, P., Barnsley, M., Hobson, P., Disney, M., Roberts, G., Dunderdale, M., Doll, C., D’Entremont, R. P., Hu, B., Liang, S., Privette, J. L., and Roy, D.: First operational BRDF, albedo nadir reflectance products from MODIS, Remote Sens. Environ., 83, 135-148, https://doi.org/10.1016/S0034-4257(02)00091-3, 2002.

Siegfried, M., Hawley, R., and Burkhart, J.: High-Resolution Ground-Based GPS Measurements Show Intercampaign Bias in ICESat Elevation Data Near Summit, Greenland, IEEE T. Geosci. Remote, 49, 3393-3400, https://doi.org/10.1109/TGRS.2011.2127483, 2011.

Stamnes, K., Tsay, S. C., Wiscombe, W., and Jayaweera, K.: Numerically stable algorithm for discrete-ordinate-method radiative transfer in multiple scattering and emitting layered media, Appl. Optics, 27, 2502-2509, 1988.

Stroeve, J., Box, J. E., Wang, Z., Schaaf, C., and Barrett, A.: Re-evaluation of MODIS MCD43 Greenland albedo accuracy and trends, Remote Sens. Environ., 138, 199-214, https://doi.org/10.1016/j.rse.2013.07.023, 2013.

Stroeve, J. C., Box, J. E., Gao, F., Liang, S., Nolin, A., and Schaaf, C.: Accuracy assessment of the MODIS 16day albedo product for snow: comparisons with Greenland in situ measurements, Remote Sens. Environ., 94, 46-60, https://doi.org/10.1016/j.rse.2004.09.001, 2005.

Stroeve, J. C., Box, J. E., and Haran, T.: Evaluation of the MODIS (MOD10A1) daily snow albedo product over the Greenland ice sheet, Remote Sens. Environ., 105, 155-171, https://doi.org/10.1016/j.rse.2006.06.009,2006.
Tsay, S.-C., Stamnes, K., and Jayaweera, K.: Radiative energy budget in the cloudy and hazy arctic, J. Atmos. Sci., 46, 1002-1018, 1989.

Wang, Z., Schaaf, C. B., Chopping, M. J., Strahler, A. H., Wang, J., O.Román, M., Rocha, A. V., Woodcock, C. E., and Shuai, Y.: Evaluation of Moderate-resolution Imaging Spectroradiometer (MODIS) snow albedo product (MCD43A) over tundra, Remote Sens. Environ., 117, 264-280, 2012.

Wang, Z., Schaaf, C. B., Strahler, A. H., Chopping, M. J., Román, M. O., Shuai, Y., Woodcock, C. E., Hollinger, D. Y., and Fitzjarrald, D. R.: Evaluation of MODIS albedo product (MCD43A) over grassland, agriculture and forest surface types during dormant and snow-covered periods, Remote Sens. Environ., 140, 60-77, https://doi.org/10.1016/j.rse.2013.08.025, 2014.

Warren, S. G.: Can black carbon in snow be detected by remote sensing?, J. Geophys. Res.-Atmos., 118, 779-786, https://doi.org/10.1029/2012JD018476, 2012.

Warren, S. G. and Wiscombe, W. J.: A Model for the spectral albedo of Snow. II: Snow Containing Atmospheric Aerosols, J. Atmos. Sci., 37, 2734-2745, 1980.

Wendisch, M., Müller, D., Schell, D., and Heintzenberg, J.: An Airborne Spectral Albedometer with Active Horizontal Stabilization, J. Atmos. Ocean. Tech., 18, 1856-1866, https://doi.org/10.1175/15200426(2001)018<1856:AASAWA>2.0.CO;2, 2001.

Wiscombe, W. and Warren, S.: A model for the spectral albedo of snow. I: Pure snow, J. Atmos. Sci., 37, 2712-2733, 1980.

Wright, P., Bergin, M., Dibb, J., Lefer, B., Domine, F., Carman, T., Carmagnola, C., Dumont, M., Courville, Z., Schaaf, C., and Wang, Z.: Comparing MODIS daily snow albedo to spectral albedo field measurements in Central Greenland, Remote Sens. Environ., 140, 118-129, https://doi.org/10.1016/j.rse.2013.08.044, 2014. 